


\section{Article Artículo Paper Diversitat sexual, 2 envelliment i treball social. De la necessitat d'espais segurs a la possibilitat de serveis residencials col.laboratius}

\section{Josep Maria \\ Mesquida ${ }^{1}$}

\section{Violeta Quiroga}

\section{Adela Boixadós ${ }^{3}$}

\section{Resum}

Aquest article vol mostrar la inadequació dels actuals serveis per a persones grans a les expectatives de lesbianes, gais, trans* i bisexuals (LGTB), així com divulgar les alternatives suggerides pels participants en la recerca que, sobre la seva situació, es va realitzar a Barcelona entre els anys 2013 i 2015. Es basa en la informació recollida a partir d'un grup de discussió format per 6 professionals que treballen amb persones grans al tercer sector, 4 entrevistes en profunditat a professionals dels serveis socials que s'identifiquen com a persones LGTB, i 243 enquestes contestades en línia per persones LGTB majors de 50 anys que viuen a la ciutat de Barcelona. Els resultats mostren que tant els professionals com les persones LGTB participants consideren que els actuals serveis per a persones grans són poc satisfactoris i es proposen accions de millora orientades a proporcionar major seguretat, així com la

1. Treballador social. Llicenciat en Ciències del Treball. Professor de Treball Social. Universitat de Barcelona.

2. Treballadora social. Antropòloga. Doctora en antropologia. Professora de Treball Social. Universitat de Barcelona.

3. Sociòloga. Professora de Treball Social. Universitat de Barcelona. 
creació de nous serveis residencials que permetin un major control que els actuals per part de les persones usuàries.

Paraules clau: Diversitat sexual, envelliment, treball social, habitatge col·laboratiu

\begin{abstract}
This article aims to show the inadequacy of current services for seniors to the expectations of gay, lesbian, trans* and bisexual people (LGTB). It also seeks to disclose the alternatives suggested by the participants in the research carried out in Barcelona on the situation of the group between 2013 and 2015. It is based on information collected from a discussion group made up of 6 professionals working with older persons in third sector organizations, 4 interviews to social service professionals who identify as LGBT, and 243 completed questionnaires online answered by over 50 LGBT people living in the city of Barcelona. The results show that current senior services are unsatisfactory and improvement measures aimed at providing them greater security and the creation of new residential services that allow greater control by the users are proposed.
\end{abstract}

Keywords: Sexual diversity, aging, social work, cohousing

\title{
Resumen
}

Este artículo persigue mostrar la inadecuación de los actuales servicios para personas mayores a las expectativas de gais, lesbianas, bisexuales y trans* (LGTB), así como divulgar las alternativas sugeridas por los participantes en la investigación realizada sobre su situación entre los años 2013 y 2015. Se basa en la información recogida a partir de un grupo de discusión formado por 6 profesionales que trabajan con persones mayores en organizaciones del tercer sector, 4 entrevistas en profundidad a profesionales de servicios sociales que se identifican como personas LGTB, y 243 cuestionarios contestados en línea por persones LGTB mayores de 50 años que viven en la ciudad de Barcelona. Los resultados muestran que los actuales servicios para persones mayores son poco satisfactorios y se proponen acciones de mejora de los mismos orientadas a proporcionar mayor seguridad, así como la 
creación de nuevos servicios residenciales que permitan un mayor control por parte de las personas usuarias.

Palabras clave: Diversidad sexual, envejecimiento, trabajo social, covivienda 


\section{Presentació}

Algunes veus procedents de l'activisme $\mathrm{LGTB}^{4}$ reclamen que els programes d'atenció per a les persones grans siguin respectuosos amb la diversitat sexual i de gènere dels seus usuaris. Denuncien que l'ingrés en una residència o en un centre diürn signifiqui en moltes ocasions renunciar a la visibilitat de la seva opció sexual o expressió de gènere. Per a les generacions que avui comencen a fer-se grans, poder viure la seva sexualitat amb cert grau de respecte i reconeixement ha estat un guany molt costós en termes personals i colllectius que es pot veure novament limitat al requerir de la cura i l'atenció aliena. De fet, el reclam de moltes persones grans LGTB que diu -no volem tornar a l'armari- posa de manifest els problemes derivats de l'envelliment en la seva intersecció amb la diversitat sexual y de gènere. Però a més a més, demostra que els serveis d'atenció no poden quedar aliens a aquesta realitat que provoca que siguin vistos amb desconfiança i por.

Aquest treball es basa en la recerca Persones grans LGTB a la ciutat de Barcelona realitzada durant el període que va des del setembre de l'any 2013 al gener de l'any 2015 (Mesquida, Quiroga i Boixadós, 2014; 2015). La investigació ha estat portada a terme per un equip investigador que pertany al Grup de Recerca i Innovació en Treball Social (GRITS) de la Universitat de Barcelona i ha comptat amb el finançament de l'Ajuntament de Barcelona i la colllaboració de la fundació Enllaç5.

\section{Treball social, diversitat sexual i expressió de gènere}

Payne (2006) defensa que tota pràctica de treball social es realitza partint d'uns fonaments ètics concrets que condicionen la forma com es perceben els problemes socials així com les accions que es duen a terme. Tradicionalment, la sexualitat ha estat un tema que en el treball social s'ha abordat des de concepcions funcionalistes o reparadores (Howe, 1999), alineant-se sovint amb posicions conservadores o emparades en la mirada clínica. Des d'aquesta perspectiva, l'homosexualitat i la transsexualitat, han estat una amenaça a

4. L'expressió LGTB és l'acrònim format per les inicials de les paraules Lesbianes, Gais, Trans* i Bisexuals.

5. La Fundació Enllaç és una organització ciutadana que ofereix accions de suport i dinamització social a persones LGTB en situació de vulnerabilitat social. www.fundacioenllac.cat 
l'harmonia familiar i a l'ordre social, i per tant quelcom que s'havia d'evitar, condemnar i sancionar. Avui dia, noves mirades han permès que la diversitat sexual i de gènere puguin ser considerades com a un àmbit per al treball social, ja que permet treballar situacions específiques de desavantatge social. A més, el treball social pot fer visibles les desigualtats que s'articulen a través del biaix sexual i de gènere.

La diversitat sexual comença a dibuixar-se com una oportunitat per a la professió durant els primers anys 90 a conseqüència de l'epidèmia de la SIDA. En aquell moment, moltes organitzacions ciutadanes van reaccionar davant d'un problema sanitari i social que superava la voluntat i les possibilitats de resposta de l'administració pública. Les organitzacions van començar a proporcionar diversos serveis d'atenció i suport per a persones afectades per la malaltia, entre els que sovint es trobava l'assistència d'un o una treballadora social que, a més de l'atenció social als afectats, també contribuïa a fer visible al col·lectiu LGTB, així com a reivindicar la necessitat d'organitzar la prevenció de la transmissió del virus a partir de les particularitats derivades de l'opció sexual.

Per altra banda, l'emergència del treball social feminista (Dominelli i Mc leod, 1999; Báñez, 2004, entre altres) permet treballar, amb noves perspectives, qüestions com el treball sexual o la violència de gènere, i apunta cap al patriarcat com el causant de les desigualtats que afecten les persones LGTB. Més recentment, l'homofòbia i la transfòbia, han estat identificades com formes d'opressió que han de ser abordades pel treball social (Maroto, 2006).

La situació de les persones LGTB en termes d'igualtat jurídica ha avançat notablement durant els últims anys, especialment per a lesbianes i gais, però en menor mida per a les persones transsexuals o bisexuals. Es indiscutible que l'acceptació social ha augmentat (Calvo, 2003; Villaamil, 2004). S’ha produït el reconeixement legal de les parelles del mateix sexe en condicions d'igualtat amb les parelles heterosexuals. També s'ha reconegut la possibilitat d'adopció per part de les parelles lesbianes i gais, el que ha generat el reconeixement institucional de nous models de famílies (Pichardo, 2009). La llei reguladora de la rectificació registral de la menció relativa al sexe de les persones també ha brindat algunes oportunitats per a les persones transsexuals. El sociòleg Jordi Monferrer (2010) defensa que l'evolució de l'activisme LGTB apunta cap al treball amb noves qüestions que, en el seu conjunt, ofereixen oportunitats per al treball social: l'acompanyament a aquestes noves famílies, la intervenció a 
favor de les persones LGTB més joves, les accions socioeducatives en contra de l'homofòbia i la transfòbia, i també la situació de les persones grans LGTB ${ }^{6}$.

\section{Treball social amb persones grans LGTB}

Els problemes que es poden presentar quan una persona envelleix sí que constitueixen una qüestió tradicionalment abordada per la disciplina del treball social. Els estats de dependència ocupen moltes pàgines a la literatura sobre treball social (Hidalgo, 2010). Igualment, són objecte del treball social els maltractaments a les persones grans (Tabueña, 2006) i la promoció de les condicions que permeten a aquestes persones assolir un bon nivell de benestar (Moreno, 2004). En aquest sentit, cal fer esment dels treballs realitzats al voltant dels conceptes d'envelliment actiu o envelliment amb èxit (Fernández-García, 2013). Finalment, també es tracten des del treball social qüestions relatives a les xarxes de suport, incloent l'atenció a familiars i cuidadors (Gómez, 2012).

Des del punt de vista de la pràctica professional, existeix una gran presència de treballadores i treballadors socials intervenint amb persones grans. A Catalunya, un estudi sobre la situació de la professió mostra que un 38 \% de les persones que fan treball social en serveis socials especialitzats ho fa amb persones grans (Col-legi Oficial de Diplomats en Treball Social i Assistents Socials de Catalunya, 2008). D'altre banda, l'estudi d'Alba Torices (2013), basant-se en dades recollides l'any 2010 sobre la professió en tot l'Estat, indica que un $14,85 \%$ de les persones participants treballen amb persones grans. Per tant, es constata que l'atenció a les persones grans és una de les activitats que ocupa a un major nombre de treballadores i treballadors socials.

Però durant els últims anys s'ha fet visible que el conjunt de les persones grans presenta una gran diversitat (Rodríguez et al., 2013). És per aquest motiu pel que sorprèn l'escassa dedicació al disseny de serveis que representin opcions innovadores compatibles amb la varietat d'estils de vida que presenta aquest col·lectiu. Tot i així, durant els últims

6. Hi ha més qüestions que actualment també motiven la mobilització de grups LGTB organitzats, com les practiques queer i els transfeminismes. L'acció col-lectiva al voltant d'aquests temes sovint no comporta intervencions que puguin identificar-se clarament com accions socials o educatives, però no es pot obviar el seu potencial caràcter transformador. 
anys ha crescut l'interès per una modalitat de recurs residencial adient per a persones $\mathrm{i}$ grups que desitgen gaudir de la prestació d'un servei amb un molt alt nivell de personalització i coherència amb els projectes de vida dels subjectes beneficiaris. Es tracta de la modalitat que en anglès és anomenada cohousing (Durrett, 2009) i que ha estat traduïda com covivienda en castellà (Zaragoza, 2014). Aquest article fa servir el concepte habitatge col-laboratiu perquè d'aquesta manera es posa l'èmfasi en el que es considera que és la seva principal característica: la implicació col·lectiva. Aquest tipus d'habitatge és un recurs social dissenyat i gestionat pel grup persones usuàries del mateix. Implica alguna mena d'associació formal, una estructura física amb un nombre limitat de places i, sobretot, un projecte de convivència basat en criteris d'afinitat i elecció.

En relació amb les seves necessitats específiques, les persones grans LGTB poden presentar una sèrie de circumstàncies que condicionarien la seva qualitat de vida en termes de fragilitat i vulnerabilitat. En aquest sentit, cal fer esment dels efectes físics i psicosocials de la discriminació que s'han acumulat al llarg de tot el cicle de vida (Friedman, 1999); la relativa falta de capital social en comparació amb les persones grans heterosexuals i cisgèneres $^{7}$ (Higgins et al., 2011); la falta d'adequació dels serveis assistencials a les necessitats del collectiu LGTB (Brotman, Ryan i Cormier, 2003); i, finalment, la intersecció entre la creixent necessitat de suport formal i la resistència d'una part de les persones grans LGTB per accedir als serveis socials i de salut preocupats per la manera com seran tractats (Westwood et al., 2015).

Tanmateix, caldrà tenir present el canvi produït en els discursos sobre l'homosexualitat, així com els efectes que aquest procés pot haver generat entre les persones més grans. Rosenfeld (1999) assegura com les estratègies d'adaptació a l'entorn de les persones LGTB són diferents en funció del discurs dominant. Seguint la seva argumentació, que es refereix al context nord-americà, es poden caracteritzar dos discursos que s'expliquen a la taula 1: el primer es correspon a l'època anterior als fets d'Stonewall ${ }^{8}$ i el segon al període posterior a aquests fets.

7. Les persones cisgènere són aquelles en les que hi ha identificació amb el gènere que correspon al sexe de naixement. Es podria dir que una persona cisgènere és a la identitat de gènere el que una persona heterosexual és a l'orientació sexual.

8. El 28 de juny de l'any 1969, un grup de clients d'un establiment gai denominat Stonewall, davant la constant pressió policial, es rebel·la protagonitzant una revolta urbana que esdevé un mite i un model a seguir a la resta del món. Actualment, el 28 de juny se celebra el Dia de l'Orgull LGTB. 
Taula 1. Discursos sobre l'homosexualitat

\begin{tabular}{|l|l|l|}
\hline Época & \multicolumn{1}{|c|}{$\begin{array}{c}\text { Homosexualitat } \\
\text { com a estigma }\end{array}$} & \multicolumn{1}{c|}{$\begin{array}{c}\text { Homosexualitat } \\
\text { com a estatus }\end{array}$} \\
\hline En relació amb la persona & $\begin{array}{l}1920 / 1970 \\
\text { (Abans Stonewall) }\end{array}$ & $\begin{array}{l}1970 / \text { Actualitat } \\
\text { (Després Stonewall) }\end{array}$ \\
\hline Implicació per a la persona & Vergonya & Tret essencial \\
\hline Àmbit on s'expressa & Privat & Orgull \\
\hline Competència & Basada en la dissimulació & Privat i públic \\
\hline Incompetència & Fracassa qui és descobert/a & Fracassa qui no ho reconeix \\
\hline
\end{tabular}

Font: Rosenfeld (1999)

Al nostre entorn els condicionants socials i històrics fan que la transformació dels discursos i de les identitats tingui lloc de forma diferent i alguns anys més tard respecte dels Estats Units. Malgrat això, es pot considerar que l'alliberament sexual viscut per la societat espanyola durant els anys setanta i vuitanta significa un punt d'inflexió comparable al procés seguit pels Estats Units als anys seixanta que van donar lloc a les revoltes d'Stonewall. En relació a aquesta qüestió, Guasch (1991) i Ugarte (2011) han descrit el canvi produït quant a les característiques de les identitats homosexuals a partir de la transició política, que comporten una major visibilitat i institucionalització.

Des del punt de vista del benestar personal, això significa que algunes persones poden haver tingut problemes d'adaptació en el procés de trànsit d'un model cap a l'altre. Així, les persones socialitzades durant els anys anteriors a l'alliberament gai poden viure amb malestar l'exposició publica d'afecte entre persones del mateix sexe i, alhora, poden ser vistes per les persones joves com reprimides, covardes o incapaces d'assumir públicament la seva identitat. Però el més possible és que en el grup format per les persones LGTB grans hi convisquin persones amb vivències en les que es combinen característiques dels dos models resultant una realitat molt diversa i que, per tant, demana pluralitat de respostes a les seves necessitats socials.

A més, la sexualitat és un aspecte absolutament descuidat en la majoria dels serveis socials. Els equips interprofessionals habituals en els serveis per a les persones grans, orienten la seva acció a moltes dimensions que tenen a veure amb el benestar psicosocial, 
però la sexualitat continua essent un aspecte de la conducta humana que no s'aborda i, quan es fa, és de forma reactiva i s'associa a situacions problemàtiques. En conseqüència, la diversitat sexual i de gènere no és un tema que es tracti gairebé mai en els serveis per a persones grans.

Els serveis residencials són serveis socials que ofereixen una alternativa a la llar en situacions de dependència i proporcionen diferents nivells d'atenció sanitària, psicològica i social en funció del perfil de beneficiaris al qual s'adrecen. Les actituds de residents i professionals respecte a la diversitat sexual en residències per a persones grans han estat estudiades recentment per l'equip de psicòlegs liderat per Feliciano Villar. El seu treball indica que entre els residents actuals es pot percebre un alt nivell d'homofòbia que s'exemplifica amb la frase "que estiguin tan lluny de mi com sigui possible" (Villar, Serrat, Fabà i Celdran, 2015a). Pel que fa als professionals, malgrat es manifesten actituds que semblen respectuoses amb la diversitat sexual, aquestes no sempre són coherents amb la totalitat de les seves respostes. Per exemple, quan són preguntats sobre com reaccionarien davant la presència de conductes homosexuals, alguns responen que ho explicarien a les seves famílies o que demanarien als residents que no mostressin la seva orientació públicament (Villar, Serrat, Fabà i Celdran, 2015b). Finalment, cal fer esment que l'habitatge col·laboratiu ha estat valorat com una modalitat de servei segur i respectuós per a les persones grans LGTB atès l'alt nivell d'autogestió que permet (Carr i Ross, 2013).

\section{Metodologia}

La recerca que és l'origen de l'actual article persegueix conèixer la situació social de les persones grans LGTB quant a necessitats i potencialitats (Mesquida, Quiroga i Boixadós, 2015). S'ha plantejat com a una investigació de tipus mixt perquè fa ús de tècniques qualitatives i quantitatives.

Per a la realització d'aquest article es fa ús de dades procedents de tres fonts: les entrevistes realitzades a 4 persones LGTB treballadores de serveis socials, el grup de discussió format per 6 professionals de serveis per a les persones grans i, finalment, els qüestionaris contestats per 243 persones LGTB de la ciutat de Barcelona majors de cinquanta anys. A continuació s'explica aquesta elecció. 
Les entrevistes realitzades a professionals LGTB de serveis socials ens proporcionen informació procedent d'un grup de persones doblement vinculades al tema de la recerca. Són tres professionals del treball social que compten també amb altres titulacions (com psicologia, sociologia, pedagogia i història) i una persona llicenciada en psicologia. Els quatre professionals, a més, són o han estat persones implicades en diferents serveis dirigits a la població LGTB en situació de vulnerabilitat social.

Per altra banda, el grup de discussió format per professionals d'entitats d'economia social que treballen amb persones grans ens ofereix informació sobre la forma com el sector valora la situació de les persones grans LGTB.

Finalment, les preguntes de l'enquesta que hem seleccionat ens donen informació sobre la percepció que el propi colllectiu té dels serveis per a les persones grans, la forma com creuen que la seva orientació sexual o identitat de gènere pot afectar la prestació d'aquests serveis i les seves preferències pel que fa la titularitat o finançament dels mateixos. Han estat contestades mitjançant un qüestionari en línia que va ser publicitat a través de les entitats de defensa del collectiu que integren el consell municipal LGTB. També es van emetre correus des de diferents serveis municipals i es van fer servir les xarxes socials. A més, durant el període corresponent al treball de camp es van realitzar accions de difusió del qüestionari en locals d'oci, entitats associatives i esdeveniments festius.

\section{Resultats}

En relació amb les necessitats socials, les persones participants al grup de discussió format per professionals del tercer sector consideren que la situació de les persones grans LGTB no és massa diferent de la de la resta de persones grans.

"Les necessitats són exactament les mateixes perquè el que necessita una persona gran, sigui com sigui, és el mateix. Però hi ha un tema... no sé, d'acceptació per part de la resta" (Treballadora social participant al grup format per professionals d'entitats que treballen a favor de persones grans) 
No obstant això, s'expressa que el context social i històric pot haver provocat situacions de patiment i marginació que originen una característica especifica: la por a patir discriminació.

També apareix la idea que les persones LGTB més grans poden patir situacions de major aïllament perquè els vincles personals amb familiars es poden haver deteriorat a causa de conflictes i tensions relacionades amb el rebuig cap a la seva orientació sexual o identitat de gènere.

"Els casos que jo conec majoritàriament estan sols o no tenen fills, no tenen pares perquè ja tenen una edat en la que estan morts o, com a mol, [tenen] germans o germanes amb qui normalment hi ha una relació conflictiva o deteriorada" (Treballadora social participant al grup format per professionals d'entitats que treballen a favor de persones grans)

$\mathrm{Al}$ mateix temps, es creu que un element que podria estar provocant situacions de malestar és el major rebuig cap a la diversitat sexual i de gènere que presenten moltes persones que formen part de la seva generació.

Les entrevistes a professionals LGTB dels serveis socials afegeixen algunes circumstàncies que dibuixen un escenari quant a necessitats molt més complex i divers. En primer lloc, es fa esment de la dificultat d'establir relacions socials entre persones que pertanyen a diferents generacions, fet que es relaciona amb què la major part de l'oferta d'oci dirigida a persones homosexuals i trans ${ }^{* 9}$ correspon a estils de vida que magnifiquen el valor de la imatge física, la joventut i el consum. Aquet fet també provoca l'exclusió de moltes persones per raons d'aspecte físic o classe. En segon lloc, també s'assenyala que alguns fets afecten de forma particular als grups inclosos a la categoria LGTB.

"Les persones trans ho tenen pitjor perquè hi ha una sèrie de problemes de salut, econòmics, jurídics.... I això genera més dificultat i més angoixa per la persona.” (Treballadora social que s’identifica com lesbiana. Entrevista)

9. Es fa servir la paraula trans*, amb l'asterisc que en llenguatges de programació i bases de dades s'utilitza com caràcter comodí, de manera que trans* funciona com un terme paraigua que es pot fer servir per parlar de persones transsexuals, transgèneres, transvestit o altres. El concepte Trans*, amb l'asterisc, té el seu origen el l'activisme transsexual i fa referència a la diversitat de vivències i identitats que tenen en comú el fet que signifiquen ruptures respecte dels rols de gènere normatius (Platero, 2014). 
Es destaca la situació de moltes dones trans ${ }^{* 10}$ grans, que tenen ingressos baixos $\mathrm{i}$ sovint pateixen situacions d'aillament social. Aquest últim punt s'associa no només a ruptures amb famílies d'origen, sinó també a pèrdues produïdes durant els primers anys de l'epidèmia de la SIDA. Sembla que aquesta reducció de capital social no pot ser compensada amb la creació de nous vincles atesa l'absència d'espais i activitats que facilitin noves oportunitats de relació.

En relació amb els serveis per a les persones grans, tant en el grup de discussió format per entitats d'atenció a la gent gran com en les entrevistes fetes a professionals LGTB, emergeix la idea que els serveis per a persones grans no s'ajusten a les necessitats i expectatives de les persones LGTB. Bàsicament, apareixen dos temes. El primer té a veure amb el fet que els actuals serveis per a les persones grans no són percebuts per la població LGTB com a espais segurs. En general, sembla que en els recursos actuals es poden viure situacions de rebuig tant per part de les altres persones usuàries com per part de membres dels equips professionals. En aquest sentit, es considera necessari realitzar accions de sensibilització i formació que millorin el coneixement i el respecte cap al col·lectiu.

\section{"Jo faria formació a la gent que treballa en la xarxa de servei socials. Per entendre la situa- ció i que puguin donar resposta més adequada a les necessitats de les persones. Aprenentat- ge, conscienciació, sensibilització al menys com una mesura transversal....." (Treballador social que s’identifica com gai. Entrevista)}

El segon tema té a veure amb la necessitat de fer ús d'espais particulars. A pesar que en general es rebutja la idea de disposar d'establiments específics, es manifesta que per a algunes persones que pertanyen a les generacions de més edat, els serveis pensats per als membres del collectiu LGTB podrien ser interessants per dos motius: d'una banda, perquè encara no s'ha treballat en la sensibilització dels professionals que actualment hi treballen als serveis ordinaris, de manera que encara no es pot garantir que aquests puguin considerar-se com a segurs; d'altra banda, perquè aquestes generacions han viscut una realitat caracteritzada precisament per l'existència de circuits i espais segregats en els quals sí que era possible expressar-se amb llibertat.

10. És a dir persones que van néixer amb cos d'home i que han modificat la seva aparença i conductes d'acord amb el gènere femení. 
"Jo crec que a la llarga si que ha d'haver una residència per tothom, però si que estic a favor, encara que soni a "guetto", que fins que no arribem [a] aquest punt, si que hauria d'haver un entremig de residències gestionades per gais i lesbianes" (Educadora social participant al grup format per professionals d'entitats que treballen a favor de persones grans)

Amb tot, s'han ressaltat algunes circumstàncies que poden considerar-se com a potencialitats. En el grup de discussió es valora l'existència de xarxes d'amistats que poden haver compensat l'absència de lligams sòlids amb les famílies procurant suport i cura en moments de necessitat. A més, dues de les persones LGTB professionals dels serveis socials entrevistades apunten cap a l'existència d'un entorn associatiu que evoluciona cap a la intervenció en l'àmbit familiar, on la qüestió de les persones grans pot arribar a constituir-se com un nou objecte d'interès, com ho està essent tot allò relacionat amb les persones LGTB més joves.

A continuació s'analitzen les respostes donades per persones grans LGTB a través del qüestionari en línia.

La taula que es mostra presenta els resultats obtinguts quan s'ha formulat la pregunta següent: Com creus que la teva orientació sexual o identitat de gènere pot afectar a l'hora de rebre un servei de qualitat?

\section{Taula 2. Com creus que la teva orientació sexual o identitat de gènere pot afectar a} l'hora de rebre un servei de qualitat?

\begin{tabular}{|l|c|}
\hline Falta de respecte a la meva identitat de gènere o orientació sexual & $47,3 \%$ \\
\hline No rebre serveis sensibles a les necessitats de les persones LGTB & $38,3 \%$ \\
\hline No tenint la meva parella reconeguda & $32,1 \%$ \\
\hline Per res, de cap manera & $31,3 \%$ \\
\hline Rebre menys atenció de qualitat & $23,9 \%$ \\
\hline Nc & $3,7 \%$ \\
\hline
\end{tabular}

Font: (Mesquida, Quiroga i Boixadós, 2015).

Així, les persones participants, de forma majoritària, consideren que la seva orientació sexual o identitat de gènere pot influir negativament en la qualitat dels serveis gerontològics. 
També s'ha preguntat en relació amb el tipus de servei residencial que, arribat el moment en el qual aquest sigui necessari, es considera preferent. A continuació es mostren les dades obtingudes:

\section{Taula 3. Quines serien les tres prioritats en cas que fos necessari} rebre assistència residencial?

\begin{tabular}{|l|c|c|c|}
\hline & Prioritat 1 & Prioritat 2 & Prioritat 3 \\
\hline $\begin{array}{l}\text { A casa meva amb els serveis que calgui } \\
\text { Habitatges amb serveis (Vida independent però }\end{array}$ & $\mathbf{6 3 , 4} \%$ & $11,9 \%$ & $14,0 \%$ \\
\hline $\begin{array}{l}\text { Habitatges tutelats (Una persona externa cuida } \\
\text { del funcionament) }\end{array}$ & $7,0 \%$ & $\mathbf{5 1 , 0} \%$ & $12,3 \%$ \\
\hline Residència & $2,1 \%$ & $3,7 \%$ & $13,6 \%$ \\
\hline Altra opció & $1,2 \%$ & $2,5 \%$ & $1,6 \%$ \\
\hline NC & $1,6 \%$ & $4,1 \%$ & $11,5 \%$ \\
\hline
\end{tabular}

Font: (Mesquida, Quiroga i Boixadós, 2015).

Els resultats mostren que la major part de les persones participants opta per models residencials poc institucionalitzats que permetin una gran autodeterminació.

S'ha preguntat en relació amb la necessitat de disposar de serveis residencials específicament dirigits a la població LGTB.

Taula 4. Són necessaris serveis residencials específics per a les persones LGTB?

\begin{tabular}{|lc|}
\hline Totalment o força necessari & $\mathbf{7 0 , 0} \%$ \\
\hline Totalment necessari & $26,7 \%$ \\
\hline Força necessari & $43,2 \%$ \\
\hline Poc o gens & $\mathbf{2 6 , 3 \%}$ \\
\hline Poc necessari & $16,5 \%$ \\
\hline Gens necessari & $9,9 \%$ \\
\hline Ns/Nc & $\mathbf{3 , 7 \%}$ \\
\hline
\end{tabular}

Font: (Mesquida, Quiroga i Boixadós, 2015). 
De manera que es pot afirmar que la major part de les persones que han participat en l'enquesta valora positivament l'existència de recursos residencials que tinguin a la població LGTB com a principal o única destinatària.

També s'ha volgut conèixer quines eren les prioritats quant a les necessitats que plantegen els actuals serveis per a les persones grans en relació amb el respecte cap a les persones LGTB:

Taula 5. Nivell de necessitat que tenen els serveis que es relacionen?

\begin{tabular}{|l|l|}
\hline Serveis socials respectuosos amb les persones LGTB & 9,03 \\
\hline Assistència mèdica respectuosa per a persones LGTB & 8,49 \\
\hline Grups de suport per a persones LGTB & 8,34 \\
\hline Advocats/serveis jurídics especialitzats en temes LGTB & 7,93 \\
\hline Opcions d'habitatge tutelat o assistits per a persones LGTB & 7,85 \\
\hline Ajudes per mantenir a una persona gran LGTB a casa & 7,45 \\
\hline Centre social per a persones LGTB & 7,44 \\
\hline Residències per a persones LGTB & 7,41 \\
\hline $\begin{array}{l}\text { Serveis assistencials especifics per a persones LGTB } \\
\text { (Tele assistència, ajuda a domicili) }\end{array}$ & 6,55 \\
\hline Assistència mèdica específica per a persones LGTB & 5,75 \\
\hline
\end{tabular}

Font: (Mesquida, Quiroga i Boixadós, 2015).

En aquest cas, s'oferia a les persones participants una llista d'opcions i aquestes valoraven la necessitat en una escala que anava de l'1 al 10. Així, els resultats que es mostren són el valor mitjà obtingut per a cadascuna de les respostes. Com es pot veure, el que es considera prioritari és que els recursos gerontològics siguin respectuosos amb el collectiu, però obtenen puntuacions altes els serveis residencials específicament dissenyats per la població LGTB, mentre que les puntuacions més baixes corresponen a altres dispositius assistencials no residencials específicament orientats al col·lectiu, com ara la tele-assistència, l'ajuda a domicili o l'assistència mèdica. De manera que el fet que els serveis s'adrecin principal o únicament a la població LGTB només és una preferència clara quan es tracta de residències, mentre que per als serveis diürns o domiciliaris sembla que aquesta especificitat és menys desitjada.

Finalment, s'ha inclòs una pregunta referida a qui es pensava que havia de ser responsable de la provisió de tots aquests serveis. Es mostren els següents resultats: 
Gràfic 1: Responsabilitat respecte de la provisió dels serveis

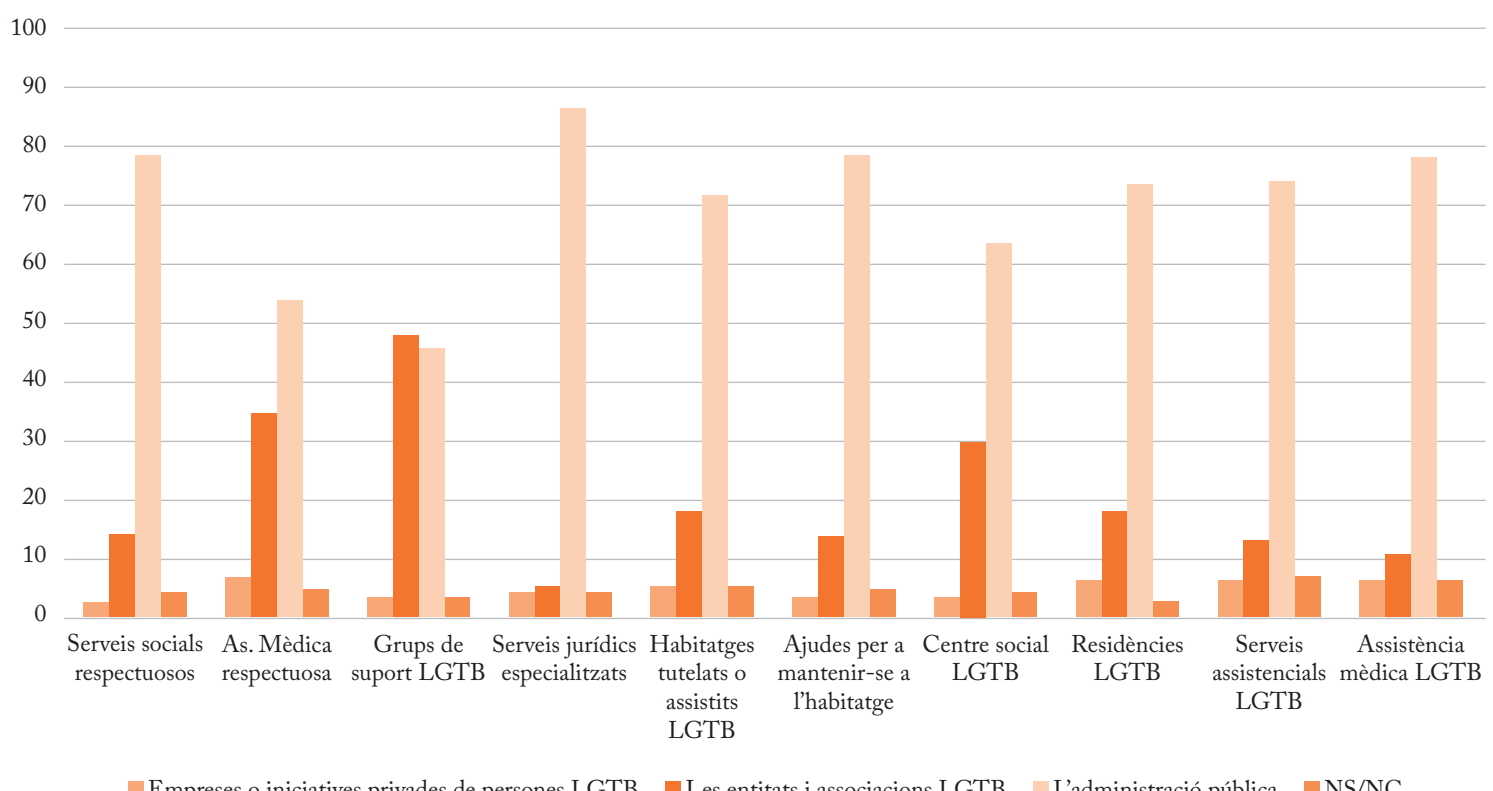
Font: Elaboració pròpia a partir de les dades obtingudes a la Enquesta sobre les persones gais, lesbianes i bisexuals de la ciutat de Barcelona (Mesquida, Quiroga i Boixadós, 2015).

Les organitzacions associatives LGTB sembla que poden tenir un paper important en la provisió de grups de suport (47,7\%), assistència mèdica respectuosa amb la diversitat sexual (35\%) i centres socials LGTB (30 \%). Però es considera que l'administració pública hauria de ser proveïdora preferent dels serveis dirigits a les persones LGTB, tant pel que $\mathrm{fa}$ als serveis ordinaris que puguin ser considerats com a respectuosos, com pel que fa als serveis socials específicament pensats per al col-lectiu. Sembla que la població LGTB participant en l'estudi aposta per un règim de benestar en el qual l'administració garanteix la prestació de la major part dels serveis sense renunciar a que el mateix col-lectiu pugui oferir determinats recursos socials i sanitaris.

\section{Discussió}

Hi ha dos conceptes en relació als quals es considera necessari fer una reflexió atenent als resultats obtinguts. $\mathrm{El}$ primer és el de espais segurs i el segon és el de la necessitat de serveis residencials col-laboratius. 
Raquel (Lucas) Platero (2014: 195), referint-se a la necessitat d'aconseguir entorns educatius segurs per a les persones trans* explica que un espai segur és aquell on no només es vetlla per reduir les agressions i la discriminació, sinó també on es produeix un clima positiu. Els espais segurs haurien de fer servir una terminologia inclusiva i haurien de posar en contacte a l'alumnat amb associacions o persones del col-lectiu que compartissin les seves experiències (Case i Meier, 2014 a Platero, 2014).

Cal avançar cap a la conceptualització de com han de ser els serveis socials que puguin identificar-se com a segurs per a les persones LGTB. En aquest sentit, la proposta de Case i Meier (2014 a Platero, 2014) sembla un bon punt de partida i apunta cap a intervencions socioeducatives desenvolupades als serveis que permetin treballar formes d'expressió inclusives i també oferir imatges positives del collectiu. Algunes persones han fet propostes sobre els continguts i habilitats que es poden treballar en els serveis per a persones grans amb l'objectiu de millorar el benestar de les persones LGTB usuàries. Així, l'equip de recerca liderat per la treballadora social americana Karen Fredriksen-Goldsen (2014) identifica les competències clau que han de ser desenvolupades a través d'aquestes accions. Entre d'altres, inclouen les següents: analitzar les pròpies actituds en relació amb la diversitat sexual, entendre com el context social pot haver impactat negativament en les persones LGTB més grans, identificar similituds i diferències entre els subgrups que conformen el col·lectiu, fer servir teories sobre l'envelliment que permetin la millora de les pràctiques professionals amb aquestes persones, garantir que es faci servir un llenguatge respectuós, i finalment, entendre com la cultura i les normes del servei i del marc legal poden facilitar o perjudicar el seu benestar.

La segona idea fa referència a la necessitat d'explorar models residencials que contemplin una gran implicació per part de les persones usuàries o dels seus representants, tant en el disseny com en la creació i gestió dels mateixos. Les dades apunten a l'administració pública com a proveïdor preferent de serveis per a les persones grans, però en menor proporció també assenyalen cap a la iniciativa social, que podria articular-se partint de les actuals estructures associatives amb les que compta el col·lectiu. Fórmules cooperatives basades en l'ajuda mútua, i combinades amb diferents nivells d'implicació pública, podrien ser respostes viables en territoris on la densitat de població LGTB ho permetés, però semblen de difícil aplicació en escenaris no urbans. Per altra banda, una lectura poc profunda ens podria portar a pensar que estem davant d'una manifestació del que s'acostuma a caracteritzar com a tendència del col-lectiu a auto-segregar-se. I naturalment, en 
un entorn caracteritzat per una gran escassetat de recursos, la idea que un grup de persones que presenta alguna característica particular aspiri a rebre el suport financer que li permeti donar cobertura a les seves necessitats, al marge de la resta de la població, és percebuda com a injusta o contrària als principi de integració i universalitat. Però possiblement, no s'ha d'entendre aquesta demanda com una reivindicació per compartir espais únicament amb altres persones LGTB, sinó com una forma de tenir major control sobre les polítiques de respecte i inclusió de la diversitat en aquests serveis.

\section{Bibliografia}

Báñez, T. (2004). El trabajo social en Aragón. El proceso de profesionalización de una actividad feminizada. Tesis doctoral. Universidad Rovira y Virgili de Tarragona. (Text disponible a http://www.tdx.cat/handle/10803/8412)

Brotman, S., Ryan, B. i Cormier, R. (2003). The health and social service needs of gay and lesbian elders and their families in Canada. The Gerontologist, 43(2), 192-202.

Calvo, K. (2003). Actitudes sociales y homosexualidad en España. En O. Guasch i O. Viñuales (eds.), Sexualidades. Diversidad y control social (299-320). Barcelona: Bellaterra.

Carr, S., i Ross, P. (2013). Assessing current and future housing and support options for older LGB people. York: Joseph Rowntree Foundation.

Case, K. A., i Meier, S. C. (2014). Developing allies to transgender and gender-nonconforming youth: Training for counselors and educators. Journal of LGBT Youth, 11(1), 62-82.

Col-legi Oficial de Diplomats en Treball Social i Assistents Socials de Catalunya (2008). La situació professional dels treballadors socials i assistents socials de Catalunya. Barcelona: Col·legi Oficial de Diplomats en Treball Social i Assistents Socials de Catalunya.

Dominelli, L. i Mac_leod, E. (1999). Trabajo social feminista. Madrid: Ediciones Cátedra, Colección Feminismos. 
Durrett, C. (2009). The senior cohousing handbook: A community approach to independent living. Canadà: New Society Publishers.

Fernández-García, T. i Ponce-de-León-Romero, L. (2013). Envejecimiento activo: recomendaciones para la intervención social desde el modelo de gestión de casos. Portularia: Revista de Trabajo Social, 13(1), 87-97.

Fredriksen-Goldsen, K. Hoy-Ellis, Ch. Goldsen, J Charles A. Emlet i Nancy R. Hooyman (2014) Creating a Vision for the Future: Key Competencies and Strategies for Culturally Competent Practice With Lesbian, Gay, Bisexual, and Transgender (LGBT) Older Adults in the Health and Human Services, Journal of Gerontological Social Work, 57(2-4), 80-107

Friedman, R. C. (1999). Homosexuality, psychopathology, and suicidality. Archives of General Psychiatry, 56(10), 887-888.

Gómez, L. (2012). El treball social amb famílies de pacients ingressats a unitats de llarga estada sociosanitària. Revista de Treball Social, 197, 102-108.

Guasch, O. (1991). La sociedad rosa. Barcelona: Anagrama.

Guasch, O. (2006). Héroes, cientificos, heterosexuales y gays. Barcelona: Bellaterra.

Hidalgo, A. (2010). Trabajo Social en el ámbito de la Ley de Dependencia. Reflexiones y sugerencias. (1º ED.). La Coruña: Netbiblo.

Higgins, A., Sharek, D., McCann, E., Sheeran, F., Glacken, M., Breen, M., y Mc Carron, M. (2011). Visible lives: Identifying the experiences and needs of older lesbian, gay bisexual and transgender people in Ireland. Dublin: Gay and Lesbian Equality Network.

Howe, D. (1999). Dando sentido a la práctica. Una introducción a la teoria del Trabajo Social. Granada: Editorial Maristán. 
Maroto, Á. L. (2006). Homosexualidad y trabajo social: herramientas para la reflexión e intervención profesional. Madrid: Siglo XXI.

Martínez, T. (2011). La atención gerontológica centrada en la persona. Álava: Departamento de Trabajo y Asuntos Sociales. Gobierno del País Vasco.

Mesquida, J.M., Quiroga, V. i Boixadós, A. (2014). Trabajo Social, diversidad sexual y envejecimiento. Una investigación a través de una experiencia de aprendizaje-servicio. Alternativas: cuadernos de trabajo social, 21, 177-192.

Mesquida, JM., Quiroga, V. i Boixadós A. (2015). Persones grans gais, lesbianes, trans i bisexuals a la ciutat de Barcelona. Lleida: Boira Editorial.

Moreno, J. (2004) Mayores y calidad de vida. Portularia: Revista de Trabajo Social, 4, 187-98.

Payne, M. (2006). What is professional social work? Bristol: Policy Press.

Pichardo Galán, J. I. (2009). Entender la diversidad familiar: Relaciones homosexuales y nuevos modelos de familia. Barcelona: Bellaterra.

Platero Méndez, R. (L). (2014). Trans* sexualidades: acompañamiento, factores de salud y recursos educativos. Barcelona: Bellaterra.

Rodríguez, G., Rodríguez, P., Castejón, P i Moran, E. (2013). Las personas mayores que vienen. Autonomía, solidaridad y participación social. Madrid: Fundación Pilares para la Autonomía Personal.

Rosenfeld, D. (1999). Identity work among lesbian and gay elderly. Journal of Aging Studies, 13(2), 121-144.

Tabueña M. (2006). Los malos tratos y vejez: un enfoque psicosocial. Intervención Psicosocial, 15(3), 275-292. 
Torices, A. (2013). Trabajadoras sociales del siglo XXI: su perfil actual. Madrid: Consejo General de Colegios de Trabajo Social.

Ugarte Pérez, J. (2011). Homoerotismo, identidad y resistencia. Madrid-Barcelona: Egales.

Villaamil, F. (2004). La transformación de la identidad gay en España. Madrid: Los Libros de la Catarata, coop.

Villar, F., Serrat, R., Fabà, J.i Celdrán, M. (2015a). As Long as They Keep Away From Me: Attitudes Toward Non-heterosexual Sexual Orientation Among Residents Living in Spanish Residential Aged Care Facilities. The Gerontologist, 55(6), 1006-1014.

Villar, F., Serrat, R., Fabà, J. i Celdrán, M. (2015b). Staff Reactions Toward Lesbian, Gay, or Bisexual (LGB) People Living in Residential Aged Care Facilities (RACFs) Who Actively Disclose Their Sexual Orientation. Journal of homosexuality, 62(8), 1126-1143.

Westwood, S., King, A., Almack, K., Suen, Y. T., \& Bailey, L. (2015). Good practice in health and social care provision for LGBT older people in the UK.Lesbian, Gay, Bisexual and Trans Health Inequalities: International Perspectives in Social Work, 145.

Zaragoza, G. (2014). Cooperativismo, viviendas para mayores y Servicios Sociales. Revista Vasca de Economía Social-Gizarte Ekonomia Euskal Aldizkaria, (10). 
Xedagogia i Treball Social

Revista de Ciències Socials Aplicades

Edita: Universitat de Girona

Disseny i maquetació: info@clam.cat · 647427732

Dipòsit Legal: GI.904-2010

ISSN: 2013-9063 